https://helda.helsinki.fi

Trajectories of multisite musculoskeletal pain in midlife : Associations with common mental disorders

\title{
Neupane, Subas
}

2020-02

Neupane , S , Lallukka , T , Pietiläinen , O , Rahkonen , O \& Leino-Arjas , P 2020 , '

Trajectories of multisite musculoskeletal pain in midlife : Associations with common mental

disorders ' , European Journal of Pain , vol. 24 , no. 2 , pp. 364-373 . https://doi.org/10.1002/ejp.1492

http://hdl.handle.net/10138/320587

https://doi.org/10.1002/ejp.1492

acceptedVersion

Downloaded from Helda, University of Helsinki institutional repository.

This is an electronic reprint of the original article.

This reprint may differ from the original in pagination and typographic detail.

Please cite the original version. 


\section{Trajectories of multisite musculoskeletal pain in midlife: Associations with}

\section{common mental disorders}

\section{Running head: CMD and multisite pain trajectories}

Subas Neupane $e^{1,2,3}$, Tea Lallukka ${ }^{3,4}$, Olli Pietiläinenn ${ }^{4}$ Ossi Rahkonen ${ }^{4}$, Päivi Leino-Arjas ${ }^{3}$

${ }^{1}$ Unit of Health Sciences, Faculty of Social Sciences, FI-33014 Tampere University, Tampere, Finland

${ }^{2}$ Gerontology Research Center, Fl-33014, Tampere University, Tampere, Finland

${ }^{3}$ Finnish Institute of Occupational Health, Helsinki, Finland

${ }^{4}$ Department of Public Health, 00014 University of Helsinki, Helsinki, Finland

Corresponding author: Dr. Subas Neupane

Unit of Health Sciences, Faculty of Social Sciences

FI-33014, Tampere University

Tampere, Finland

Email: subas.neupane@tuni.fi

Category: Original article

Word count:

Abstract: 251

Main text: 3288 (excluding abstract, key messages, references and the tables)

Number of tables: 3

Number of figures: 1

Supplementary tables: 2

Conflict of interest: None declared

This article has been accepted for publication and undergone full peer review but has not been through the copyediting, typesetting, pagination and proofreading process, which may lead to differences between this version and the Version of Record. Please cite this article as doi: 10.1002/ejp.1492

This article is protected by copyright. All rights reserved 
Funding: This work is supported by the Finnish Work Environment Fund (grant \#117141). OR is supported by the Academy of Finland (Grant \#1294514) and the Juho Vainio Foundation. TL is supported by the Academy of Finland (Grants \#287488 and \#319200) and by the Finnish Work Environment Fund (Grant \#117308).

This article is protected by copyright. All rights reserved 
Significance: Four developmental trajectories of multisite pain in midlife were described over 10-12 years of follow-up: low (41\% of the sample), increasing (24\%), high (15\%), and decreasing (20\%). Common mental disorders strongly associated with these. Belonging to the highest tertile of mental disorders at baseline increased the risk of membership in the high trajectory more than 5-fold. On the other hand, together with a decrease in mental disorders, the number of pain sites decreased to zero.

\section{Trajectories of multisite musculoskeletal pain in midlife: Associations with common mental disorders}

\section{Abstract}

Objectives: We examined developmental trajectories of multisite musculoskeletal pain in midlife, and their associations with mental well-being.

Methods: Midlife municipal employees at baseline aged 40, 45, 50, 55 or 60 years ( $80 \%$ women) from the City of Helsinki, Finland, responded to a baseline questionnaire in 2000-02 ( $N=8960$; response rate 67\%) and follow-ups in 2007 ( $N=7332 ; 83 \%)$ and 2012 ( $N=6809$; 78\%). Trajectories of the number of pain sites (0-4) were modeled using latent class growth analysis $(n=6527)$. Common mental disorders were assessed by the General Health Questionnaire (GHQ) 12-item version (trichotomized to low, intermediate or high). Information on health-related behaviour, co-morbidity and socioeconomic position was obtained from the questionnaire. Associations of baseline factors with pain trajectories were assessed by multinomial logistic regression.

Results: We identified four distinct pain trajectories: high (15\%), increasing (24\%), decreasing (20\%) and low (41\%). After an initial increase, the high and increasing trajectories stabilized at around 2.5 and 1.5 pain sites, respectively. In a multivariable model, high, increasing and decreasing trajectories of pain sites were associated with higher baseline GHQ scores. The association was strongest for the high trajectory (low GHQ: OR 3.7, 95\% Cl 2.8-4.9; high GHQ: OR 5.4, 95\% 4.4-6.6). Trajectory membership also associated with unhealthy behaviours, musculoskeletal comorbidities and a low socioeconomic position at baseline. Average GHQ was consistently highest for the high pain trajectory and decreased in the decreasing trajectory over the follow-up.

This article is protected by copyright. All rights reserved 
Conclusions: Multisite musculoskeletal pain shows variable developmental patterns among midlife employees. The trajectories are associated with the level of common mental disorders.

Key words: Multisite pain, trajectory analysis, musculoskeletal pain, common mental disorders, cohort study, midlife employees

This article is protected by copyright. All rights reserved 


\section{Introduction}

Musculoskeletal pain is very common among both the working and general populations globally, with a strong impact on the capacity to work and the total years lost due to any disability (Hoy et al., 2015). Low back pain and neck pain are the most prevalent and affect people of all age groups (GBD 2017 Disease and Injury Incidence and Prevalence Collaborators, 2018). Musculoskeletal pain occurs in several body sites concurrently more often than in a single site only in the general population (Carnes et al., 2007; Schmidt and Baumeister, 2007), among the occupationally active (Saastamoinen et al., 2006; Melkevik et al., 2018), and among older adults (Butera et al., 2019). While musculoskeletal pain in adolescence often persists to midlife (Leino-Arjas et al., 2018) and midlife pain to old age (Neupane et al., 2018), the widespreadness of pain may decrease with retirement from work (Neupane et al., 2018).

Mental disorders, themselves a high burden to society (GBD 2017 Disease and Injury Incidence and Prevalence Collaborators, 2018), increase the risk of musculoskeletal pain. Co-morbidity between pain problems and depressive and anxiety disorders has been a repeated finding (Arnow et al., 2006; Bair et al., 2003; Beesdo et al., 2010; Means-Christensen et al. 2008). General population surveys in 17 European countries showed a link of mood and anxiety disorders with multiple pains (Gureje et al., 2008). Among a random sample of people in working-age the odds of mental disorder were increased in those with chronic widespread pain (Benjamin et al., 2000). A recent study among Danish health-care workers observed a correlation between the number of pain sites and the level of depressive symptoms, and the two types of symptoms interacted in increasing the risk of long-term sickness absence (Melkevik et al., 2018).

Various working conditions have been found to associate with the persistence of multisite musculoskeletal pain (Neupane et al., 2018; Haukka et al., 2012; Neupane et al., 2017). We earlier reported among midlife municipal employees that a high multisite pain trajectory over 28 years was characterized by an initially heavy workload (high biomechanical exposures, high work demands and low level of job control) and an adverse lifestyle profile (low leisure-time physical activity and being 
overweight or obese) in addition to musculoskeletal co-morbidity (Neupane et al., 2018). Similarly, high physical and psychosocial workload, overweight or obesity and low leisure-time physical activity at baseline were associated with a high or increasing multisite pain trajectory in a two-year follow-up of female kitchen workers (Haukka et al., 2012).

While comorbidity between multisite musculoskeletal pain and mental ill-health has been observed in cross-sectional studies (Melkevik et al., 2018; Gureje et al., 2008; Benjamin et al., 2000), little is known about their longitudinal relationships. Among the general population of a Norwegian municipality, Kamaleri et al. (2009) reported a rather stable number of musculoskeletal pain sites over a 14-year followup. High common mental disorders at baseline strongly associated with the number of pain sites at follow-up, but the association did not persist when the pain variable at baseline and other covariates were accounted for. The data did not enable longitudinal growth patterns to be studied.

In the present study we aimed, first, to describe the trajectories - or sub-groups within the data with a similar tendency of development - of the number of musculoskeletal pain sites over about 10 years among midlife municipal employees. Second, we investigated whether common mental disorders associated with the trajectories. For this, we analyzed the relationship of common mental disorders assessed at baseline with trajectory membership, and the changes in the average level of common mental disorders over the follow-up by trajectory.

\section{Methods}

The study was based on the Helsinki Health Study (HHS), a well-established ongoing cohort conducted among municipal employees of the City of Helsinki, the largest employer in Finland (Lahelma et al., 2012). The City of Helsinki employees represent many different occupations from manual workers to professionals and managers.

The baseline survey was conducted among employees turning the age 40,45, 50, 55 or 60 years during 2000-2002. A questionnaire was sent to a target group of 13344 employees in total and 8960 employees replied to the questionnaire survey at baseline (response rate 67\%) (Lahelma et al., 2012). The follow-up surveys were conducted in 2007 (7332 respondents, 83\% response rate) and 2012 (6809 respondents, $78 \%$ response rate). We included a subgroup of people who participated in the baseline survey and also replied in the follow-up survey in 2012. In total 6527 subjects were included in the trajectory analysis. The numbers of those who replied in all three surveys amounted to 5847. Previous analyses of non- 
respondents support the data being broadly representative of the target population, although those with long sickness absence spells, lower socio-economic position, men, and the youngest age group were somewhat less likely to participate. However, it is unlikely that the non-response distorted or biased the analysis (Lahelma et al., 2012; Laaksonen et al., 2008). Only 10\% of those who reported multisite pain at baseline were dropped out in the follow-ups in our study.

At baseline, all participants were employed by the City of Helsinki. Participants reported their current work status in all three surveys as whether their work is full time, part-time, part-time pension, other cause for not being at work or retired.

The study was approved by the ethics committee of the Department of Public Health, University of Helsinki, and the health authorities of the City of Helsinki, Finland.

\section{Measurements of variables}

\section{Number of musculoskeletal pain sites}

In all three surveys, the subjects were inquired about current ongoing pain or ache at any site (no/yes). Those who responded in the affirmative were presented a list of potential sites including a) head and face, b) neck or shoulders, c) low back, d) one or both upper limbs, e) one or both lower limbs, f) abdominal area or g) some other site, each with the dichotomous alternatives yes or no. Responses for the musculoskeletal areas b-e were summed up into a single variable ranging from 0 (no pain) to 4 (pain in all four sites). In the trajectory analysis, we modeled the number of musculoskeletal pain sites.

\section{Common mental disorders}

As the indicator of common mental disorders we used the General Health Questionnaire (Goldberg et al., 1997) 12 -item version (GHQ-12). The GHQ-12 is considered a reliable, valid and context-free inventory of symptoms of minor non-psychotic mental health problems in the recent past, such as symptoms of anxiety, depression and self-esteem. The GHQ-12 was derived from the baseline and each follow-up survey. We categorized the score into three groups $(0=$ no, $1=$ low or 2-12 $=$ high). The cut off points were chosen based on tertiles, providing equal sized groups for the analyses.

\section{Socioeconomic position}

Socioeconomic position was defined using the occupational titles of the employees. We defined a dichotomous variable as "high" social class that includes managers and semi-professionals and "low" social class includes routine non-manual work and manual work (Virtanen et al., 2017).

This article is protected by copyright. All rights reserved 


\section{Behavioural risk factors}

Leisure time physical activity (LTPA) was measured in metabolic equivalent values (MET) and categorized into three groups following previous procedures (Lahti et al., 2014); low as under 14 total MET-

hour/week, moderate (overall MET hours more than 14 while less than 14 hours in high-intensity physical activity) and vigorous physical activity (at least 14 MET-hours/week in high-intensity physical activity).

Current smoking was measured as no or yes.

Body mass index was calculated based on self-reported height and weight, and then categorized into three groups as $<25, \geq 25$ to 29.9 or $\geq 30$.

\section{Musculoskeletal comorbidity}

Musculoskeletal comorbidity was measured using a dichotomous variable of self-reported physiciandiagnosed long-standing illnesses (osteoarthrosis, rheumatoid arthritis osteoporosis, gout). A dichotomous variable was then created by combining all four diseases and classified 0 as no diseases or $1+$ diseases.

\section{Other variables}

Age $(40,45,50,55,60$ years $)$ and gender were used as covariates.

\section{Statistical analyses}

We used latent class growth analysis (LCGA) to model the number of musculoskeletal pain sites and identify trajectories. The Poisson distribution function best represented the patterns of change in the data, considering the number of pain sites as a count variable. In LCGA, it is assumed that all individuals follow the growth pattern of random variation. Participants were included in the analysis if they had responded at least to the baseline survey and the last follow-up. The number of trajectories and their shapes were first determined. The final model was decided based on fit criteria (see supplementary Table S1) including the Akaike Information Criterion (AIC), the Bayesian Information Criterion (BIC), sample size adjusted BIC, entropy, and posterior probability of trajectory membership (Nylund et al., 2007). A lower BIC, AIC, and sample size adjusted BIC value, entropy close to one and higher posterior probabilities indicate a better model fit. Moreover, interpretability of the model was considered. Based on these, a four class-trajectory model was selected. The trajectory groups were illustrated by plotting the means of the number of pain sites against each survey year.

This article is protected by copyright. All rights reserved 
Characteristics of the study participants are first presented as frequencies and percentages by trajectory group. The mean and standard deviation are presented for the continuous variables.

Associations of the trajectories of the number of musculoskeletal pain sites with common mental disorders and socio-economic position, health-related behaviour and comorbidity were studied using multinomial logistic regression, where the low trajectory was used as the reference and the odds ratios (ORs) and their 95\% confidence intervals (Cls) were calculated for the high, increasing and decreasing trajectory groups. Two models were built: Model I (a crude model) and Model II that simultaneously adjusted for all variables (common mental disorders, age, gender, socioeconomic position, smoking, BMI, LTPA and comorbidity) used in Model I. In addition, Model II was further adjusted for the participants' work status at baseline.

The distribution of the mean values of common mental disorders and the number of pain sites in each survey are presented by trajectory group and the difference between the groups tested using ANOVA. The work status of the participants in each survey by trajectory group is also calculated and the difference between the groups tested using a Chi-Squared test.

LCGA was conducted in Mplus v7.2 and all the other analyses in Stata v14.

\section{Results}

Based on the LCGA, four distinct trajectories of the number of musculoskeletal pain sites were identified (Figure 1): low $(n=2680,41.1 \%)$, high $(n=963,14.8 \%)$, increasing $(n=1552,23.8 \%)$ and decreasing $(n=$ 1332, 20.4\%). The low group consisted of participants with the lowest mean of number of pain sites throughout the study period. Those in the high trajectory had initially two pain sites and slightly above two sites on average in the follow-up. The increasing trajectory started with low pain at baseline but later in the follow-up the participants had more than one pain site. The decreasing trajectory started with pain in one body site and had no pain after the first round of follow-up.

Table 1 shows the baseline characteristics of the study participants by trajectory group. The mean age of the participants was 49.63 years (SD 6.53), the high trajectory group being the oldest (50.47 years) and the increasing group the youngest (48.72 years). There were more men $(23 \%)$ in the low trajectory and fewer $(11 \%)$ in the high, while there were more women in the high $(89 \%)$ and fewer $(77 \%)$ in the low 
group. Regarding health-related behaviour, there were fewer smokers in the low than in the increasing trajectory. The mean BMI of all participants was 25.42 (SD 4.26), lowest in the low and highest in the high trajectory. Similarly, those having low leisure time physical activity mostly belonged to the high trajectory, while those having vigorous activity were more likely to belong to the low. Most of the participants with no musculoskeletal comorbidities belonged to the low trajectory, while more people in the high group had one or more musculoskeletal comorbidities. Comparatively more people with full time work belonged to the increasing trajectory, more people in part-time work belonged to the decreasing trajectory and those having part-time pension mostly belonged to the high trajectory. More people with high socioeconomic position belonged to the low trajectory and fewer in the high. Likewise, more people with high pain trajectory had high GHQ scores (49\%), compared to $19 \%$ of the low trajectory group.

Table 2 presents the associations of common mental disorders (GHQ-12) at baseline, and of other baseline factors, with the membership of the high, increasing and decreasing pain trajectories compared to the low. In the multivariable model (Model II), associations of both low and high common mental disorders with the high, increasing and decreasing trajectories were found. However the magnitude of the association was the highest for the contrast between the high vs. low trajectory due to low (OR 3.68, 95\% $\mathrm{Cl}$ 2.78-4.85) and high (OR 5.30, 95\% 4.31-6.53) common mental disorders; the magnitude of the association was smallest for the decreasing trajectory compared to low.

Compared to the younger age group, those aged 45 or 50 had significantly higher odds of being in the high trajectory, while significantly lower odds of being in the increasing trajectory were observed for older age group (OR for oldest age group $0.60,95 \% \mathrm{Cl} 0.44-0.82)$. Women had higher odds than men to belong to the high $(2.22,1.68-2.93)$ and increasing $(1.46,1.19-1.80)$ trajectory groups. Low socioeconomic position also associated with the high (2.02, 1.66-2.45), increasing (1.30, 1.11-1.52) and decreasing (1.29, 1.10-1.52) trajectories. Having one or more musculoskeletal comorbidities was strongly associated with the high $(5.42,4.25-6.94)$, increasing $(3.03,2.40-3.82)$ and decreasing $(2.19,1.72-2.79)$ trajectories. Overweight and obesity were also associated in all three contrasts. Smoking was associated with the high trajectory only $(1.30,1.04-1.63)$. Vigorous physical activity was associated with lower odds in relation to the increasing and decreasing trajectory group.

Table 3 shows the mean GHQ-12 scores at each survey by pain trajectory. In all surveys the mean GHQ-12 was highest for the high trajectory, while it was lowest for the low trajectory. The difference between the 
groups was statistically significant. The table also shows, by trajectory, the mean number of pain sites at each survey.

Work status of the study participants at different surveys is also presented by trajectory group (Table S2). At baseline, the great majority of the people worked full time irrespective of trajectory. By the end of the follow-up, this proportion decreased in all groups, with the sharpest decline (from $88 \%$ to $36 \%$ ) in the high pain trajectory. In that group, $63 \%$ were retired full-time or part-time or were otherwise not working by the end of the follow-up, the proportion being $46 \%$ in the low pain trajectory. Among those in the increasing and decreasing pain trajectories the proportions were $46 \%$ and $50 \%$, respectively.

\section{Discussion}

We identified four distinct trajectories of the number of musculoskeletal pain sites among midlife municipal employees over 10 to 12 years of follow-up. Less than half of the participants had consistently low or no pain, almost one fourth had an increasing number of pain sites, while about one fifth had decreasing pain. A comparatively small group of participants (15\%) had persistently high pain during follow-up. A central finding was that of a close association of the level of the common mental disorders at baseline with the diverse developmental patterns of the number of pain sites even when adjusted for socio-demographic and health-related behaviours. The participants with the highest number of pain sites also had the highest mean score of common mental disorders in all surveys, followed by the increasing trajectory. We also observed that the common mental disorders score decreased over the follow-up in the decreasing pain trajectory.

Studies on the long-term developmental patterns of musculoskeletal pain are scarce. A few earlier studies have described musculoskeletal pain from adolescence to midlife or from midlife to old age and reported 2 to 5 trajectories of any (Leino-Arjas et al., 2018) or multisite (Neupane et al., 2018) musculoskeletal pain and of chronic low back pain (Dunn et al., 2013; Kjaer et al., 2017). These studies suggest that although changes occur, musculoskeletal pain is often persistent or recurrent. Among working cohorts, a substantial proportion of subjects reported persistent multisite musculoskeletal pain (Haukka et al., 2012; Neupane et al., 2017; Airila et al., 2014). In identifying diverse developmental patterns our findings are in line with earlier studies. However, the low pain group was somewhat larger and the high persistent pain group smaller than in previous studies among food industry workers (Neupane et al., 2017) or kitchen

This article is protected by copyright. All rights reserved 
workers (Haukka et al., 2012), possibly due to differences in work exposures which in the present study may have been less strenuous on average.

Associations between musculoskeletal pain and common mental disorders have been observed in previous studies. The study by Kamaleri et al. (2009) applied a version of the same instrument (General Health Questionnaire) as we used, when assessing the association of mental distress with the number of musculoskeletal pain sites at follow-up. Comorbidity of depressive symptoms with musculoskeletal pain (Miller et al., 2009; Bair et al., 2003), and with the number of pain sites (Kato et al., 2006; Melkevik et al., 2018), has been reported. In female Danish municipal employees aged 46 years on average, $88 \%$ of those who reported medium to high levels of depressive symptoms also reported pain in one or more body sites (Melkevik et al., 2018). The study was limited to female employees. A 10-year (5 plus 5 year) follow-up of metal industry employees found reciprocal longitudinal associations between distress symptoms and musculoskeletal pain, while depressive symptoms were predictive of pain in men but not in women (Leino and Magni, 1993). In predicting long-term sickness absences, an interaction between depressive symptoms and musculoskeletal pain was found among female Danish employees (Melkevik et al., 2018). Among Finnish employees, the risk of disability retirement was 4-fold in those with co-occurring mental and musculoskeletal disorders compared to participants with neither, while having either disorder alone was associated with a 2-fold risk (Kaila-Kangas et al., 2014).

In addition to high common mental disorders, also poor health-related lifestyle, female gender, low socioeconomic position and musculoskeletal comorbidities at baseline associated with the unfavorable pain trajectories in particular. Similar findings have been reported previously (Neupane et al., 2018; Haukka et al., 2012). Vigorous leisure-time physical activity was protective of the increasing trajectory, but also similarly associated with the decreasing trajectory. While it is possible that some part of the associations is due to that people with pain problems have been encouraged to exercise more, it should be noted, that the assessment of the covariates was only made at baseline. All in all, our findings add evidence to previous research and treatment guidelines, suggesting that promoting mental well-being and healthy lifestyles might help reduce the burden of multisite musculoskeletal pain, including absence from work (Virtanen et al., 2018).

The current findings were based on three measurements among employees turning the age of $40,45,50$, 55 or 60 years in 2000-2002. Compared with the younger, people aged 45 and 50 years at baseline were in an increased risk of belonging to the high pain trajectory, and those aged 45 also to the increasing 
trajectory, while no such associations were found for the older people in the full model. This could be because people of age 45 and 50 were still mostly working full time while among the older a sizeable subgroup had retired and left work exposures behind. In line with these findings, an earlier study showed that retirement can serve to alleviate multisite musculoskeletal pain (Neupane et al., 2018).

Our study has certain methodological strengths. It was conducted in a prospective design with 10 to 12 years of follow-up in total. The data were derived from a cohort representative of midlife municipal employees of the capital of Finland, and had a good participation rate at baseline and in the follow-ups (Lahelma et al., 2012). The participants were involved in a wide range of work tasks. The outcome variable of multisite pain has been repeatedly used in the literature (Haukka et al., 2012; Neupane et al., 2017; Haukka et al., 2013). The main determinant of common mental disorders was assessed using the General Health Questionnaire (GHQ-12), which is a well-validated instrument (Lahelma et al., 2012) with a high internal consistency (Lahelma et al., 2015). The GHQ-12 measures general mental health problems such as anxiety and mild depression and predicts more severe mental disorders and need for treatment (Goldberg, 1972). We used three categories of common mental disorders based on the distribution of the score. There seems to be no consistently used threshold scores for GHQ-12. Previous studies have presented various optimal thresholds and the cut-off points differ due to diversity in the prevalence rates of psychiatric disorders and comorbid diagnoses (Ozdemir and Rezaki, 2007). Goldberg et al (1997) indicated that the most common cut-off of the score is $2 / 3$. Other studies showed a range of ideal thresholds, varying from $0 / 1$ to $5 / 6$ (Goldberg et al., 1998). Nonetheless, there are also limitations in our study. The self-reported measures are subject to potential reporting bias. We cannot rule out the so called healthy worker effect as occupational cohorts tend to be healthier than the general population. We excluded a relatively large number of participants who replied to the baseline survey because of our inclusion criteria. However, only $10 \%$ of those who reported multisite musculoskeletal pain at baseline dropped out in the follow-ups; this small number did not affect our outcome. The growth models typically require at least three repeated measures per individuals to identify enough parameters to make the growth model flexible, but using three repeated measures has been criticized to over-identify a linear trajectory (Curran et al., 2010). Our sensitivity analysis that used the data of participants who responded to the pain questions in all three surveys $(n=5847)$ found no difference in trajectory shapes and only minimal differences in group proportions compared to those reported here.

In conclusion, in midlife employees we identified diverse developmental patterns of the number of musculoskeletal pain sites during 10 to 12 years that were consistently associated with the level of

This article is protected by copyright. All rights reserved 
common mental disorders. Attempts to control multisite pain should include efforts to prevent common mental disorders.

\section{Author contributions}

T.L., O.R., O.P. and P.L-A. Participated in the study design and the surveys. P.L-A. and S.N. conceptualized the study. S.N. analyzed the data. P.L-A. and S.N. did the interpretation of the results. S.N prepared the first draft of the manuscript. The manuscript was reviewed and commented on by P.L-A., T.L, O.R. and

O.P. The final version of the manuscript was read, revised and approved by all authors.

\section{References}

Airila, A., Hakanen, J. J., Luukkonen, R., Lusa, S., Punakallio, A., \& Leino-Arjas, P. (2014). Developmental trajectories of multisite musculoskeletal pain and depressive symptoms: the effects of job demands and resources and individual factors. Psychology \& Health, 29(12), 1421-1441.

Arnow, B. A., Hunkeler, E. M., Blasey, C. M., Lee, J., Constantino, M. J., Fireman, B., ... \& Hayward, C. (2006). Comorbid depression, chronic pain, and disability in primary care. Psychosomatic Medicine, 68(2), 262268.

Bair, M. J., Robinson, R. L., Katon, W., \& Kroenke, K. (2003). Depression and pain comorbidity: a literature review. Archives of Internal Medicine, 163(20), 2433-2445.

Beesdo, K., Jacobi, F., Hoyer, J., Low, N. C., Höfler, M., \& Wittchen, H. U. (2010). Pain associated with specific anxiety and depressive disorders in a nationally representative population sample. Social Psychiatry and Psychiatric Epidemiology, 45(1), 89-104.

Benjamin, S., Morris, S., McBeth, J., Macfarlane, G. J., \& Silman, A. J. (2000). The association between chronic widespread pain and mental disorder: a population-based study. Arthritis \& Rheumatism: Official Journal of the American College of Rheumatology, 43(3), 561-567.

Butera, K. A., Roff, S. R., Buford, T. W., Cruz-Almeida, Y., Aprato, A., Conti, A., ... \& Ajmeri, A. N. (2019). The impact of multisite pain on functional outcomes in older adults: biopsychosocial considerations. Journal of Pain Research, 12, 1115-1125.

Carnes, D., Parsons, S., Ashby, D., Breen, A., Foster, N. E., Pincus, T., ... \& Underwood, M. (2007). Chronic musculoskeletal pain rarely presents in a single body site: results from a UK population study.

Curran, P., J., Obeidat, K., Losardo, D. Twelve frequently asked questions about growth curve modeling. Journal of Cognition and Development. 2010; 11(2):121-36.

This article is protected by copyright. All rights reserved 
Dunn, K. M., Campbell, P., \& Jordan, K. P. (2013). Long-term trajectories of back pain: cohort study with 7-year follow-up. BMJ open, 3(12), e003838.

GBD 2017 Disease and Injury Incidence and Prevalence Collaborators. Global, regional, and national incidence, prevalence, and years lived with disability for 354 diseases and injuries for 195 countries and territories, 1990-2017: a systematic analysis for the Global Burden of Disease Study 2017. Lancet 2018; 392: 1789-1858.

Goldberg, D. P., Gater, R., Sartorius, N., Ustun, T. B., Piccinelli, M., Gureje, O., \& Rutter, C. (1997). The validity of two versions of the GHQ in the WHO study of mental illness in general health care. Psychological Medicine, 27(1), 191-197.

Goldberg, D., P. The detection of psychiatric illness by questionnaire. London: Oxford University Press, 1972.

Goldberg, D., P., Oldehinkel, T., Ormel, J. Why GHQ threshold varies from one place to another. Psychol Med. 1998; 28:915-921.

Gureje, O., Von Korff, M., Kola, L., Demyttenaere, K., He, Y., Posada-Villa, J., ... \& Iwata, N. (2008). The relation between multiple pains and mental disorders: results from the World Mental Health Surveys. PAIN®, 135(1-2), 82-91.

Haukka, E., Kaila-Kangas, L., Ojajärvi, A., Miranda, H., Karppinen, J., Viikari-Juntura, E., ... \& Leino-Arjas, P. (2013). Pain in multiple sites and sickness absence trajectories: a prospective study among Finns. Pain, 154(2), 306-312.

Haukka, E., Ojajärvi, A., Takala, E. P., Viikari-Juntura, E., \& Leino-Arjas, P. (2012). Physical workload, leisuretime physical activity, obesity and smoking as predictors of multisite musculoskeletal pain. A 2-year prospective study of kitchen workers. Occup Environ Med, 69(7), 485-492.

Hoy, D. G., Smith, E., Cross, M., Sanchez-Riera, L., Blyth, F. M., Buchbinder, R., ... \& March, L. M. (2015). Reflecting on the global burden of musculoskeletal conditions: lessons learnt from the global burden of disease 2010 study and the next steps forward. Annals of the Rheumatic Diseases, 74(1), 4-7.

Kaila-Kangas, L., Haukka, E., Miranda, H., Kivekäs, T., Ahola, K., Luukkonen, R., ... \& Leino-Arjas, P. (2014). Common mental and musculoskeletal disorders as predictors of disability retirement among Finns. Journal of Affective Disorders, 165, 38-44.

Kamaleri Y, Natvig B, Ihlebaek CM, Benth JS, Bruusgaard D (2009). Change in the number of musculoskeletal pain sites: a 14-year prospective study. $P A I N \circledast, 141$ (1-2):25-30.

Kato, K., Sullivan, P. F., Evengård, B., \& Pedersen, N. L. (2006). Chronic widespread pain and its comorbidities: a population-based study. Archives of Internal Medicine, 166(15), 1649-1654.

This article is protected by copyright. All rights reserved 
Kjaer, P., Korsholm, L., Leboeuf-Yde, C., Hestbaek, L., \& Bendix, T. (2017). Individual courses of low back pain in adult Danes: a cohort study with 4-year and 8-year follow-up. BMC Musculoskeletal Disorders, 18(1), 28.

Laaksonen, M., Aittomäki, A., Lallukka, T., Rahkonen, O., Saastamoinen, P., Silventoinen, K., \& Lahelma, E. (2008). Register-based study among employees showed small nonparticipation bias in health surveys and check-ups. Journal of Clinical Epidemiology, 61(9), 900-906.

Lahelma, E., Aittomäki, A., Laaksonen, M., Lallukka, T., Martikainen, P., Piha, K., .. \& Saastamoinen, P. (2012). Cohort profile: the Helsinki health study. International journal of epidemiology, 42(3), 722-730.

Lahelma, E., Pietiläinen, O., Rahkonen, O., \& Lallukka, T. (2015). Common mental disorders and causespecific disability retirement. Occup Environ Med, 72(3), 181-187.

Lahti, J., Holstila, A., Lahelma, E., \& Rahkonen, O. (2014). Leisure-time physical activity and all-cause mortality. PLoS One, 9(7), e101548.

Leino, P., Magni, G. Depressive and distress symptoms as predictors of low back pain, neck-shoulder pain, and other musculoskeletal morbidity: a 10-year follow-up of metal industry employees. Pain 1993; 53:8994.

Leino-Arjas, P., Rajaleid, K., Mekuria, G., Nummi, T., Virtanen, P., \& Hammarström, A. (2018). Trajectories of musculoskeletal pain from adolescence to middle age: the role of early depressive symptoms, a $27-$ year follow-up of the Northern Swedish Cohort. Pain, 159(1), 67-74.

Means-Christensen, A. J., Roy-Byrne, P. P., Sherbourne, C. D., Craske, M. G., \& Stein, M. B. (2008). Relationships among pain, anxiety, and depression in primary care. Depression and anxiety, 25(7), 593-600.

Melkevik, O., Clausen, T., Pedersen, J., Garde, A. H., Holtermann, A., \& Rugulies, R. (2018). Comorbid symptoms of depression and musculoskeletal pain and risk of long term sickness absence. BMC Public Health, 18(1), 981.

Miller, L., R., Cano, A. Comorbid chronic pain and depression: who is at risk? J Pain. 2009; 10(6): 619-627. doi: 10.1016/j.jpain.2008.12.007.

Neupane, S., Leino-Arjas, P., Nygård, C. H., Oakman, J., \& Virtanen, P. (2017). Developmental pathways of multisite musculoskeletal pain: what is the influence of physical and psychosocial working conditions?. Occup Environ Med, 74(7), 468-475.

Neupane, S., Nygård, C. H., Prakash, K. C., von Bonsdorff, M. B., von Bonsdorff, M. E., Seitsamo, J., ... \& Leino-Arjas, P. (2018). Multisite musculoskeletal pain trajectories from midlife to old age: a 28-year follow-up of municipal employees. Occup Environ Med, 75(12), 863-870.

This article is protected by copyright. All rights reserved 
Nylund, K. L., Asparouhov, T., \& Muthén, B. O. (2007). Deciding on the number of classes in latent class analysis and growth mixture modeling: A Monte Carlo simulation study. Structural equation modeling: $A$ multidisciplinary Journal, 14(4), 535-569.

Ozdemir, H., Rezaki, M. General Health Questionnaire-12 for the detection of depression. Turk Psikiyatri Derg. 2007; 18:13-21.

Saastamoinen, P., Leino-Arjas, P., Laaksonen, M., Martikainen, P., Lahelma, E. Pain and health related functioning among middle-aged employees. J Epidemiol Community Health 2006; 60:793-8.

Schmidt C. O., Baumeister S. E. Simple patterns behind complex spatial pain reporting? Assessing a classification of multisite pain reporting in the general population. Pain 2007; 133:174-82.

Virtanen, M., Ervasti, J., Head, J., Oksanen, T., Salo, P., Pentti, J., ... \& Vahtera, J. (2018). Lifestyle factors and risk of sickness absence from work: a multicohort study. The Lancet Public Health, 3(11), e545-e554.

Virtanen, M., Lallukka, T., Ervasti, J., Rahkonen, O., Lahelma, E., Pentti, J., .. \& Kivimäki, M. (2017). The joint contribution of cardiovascular disease and socioeconomic status to disability retirement: a register linkage study. International Journal of Cardiology, 230, 222-227.

This article is protected by copyright. All rights reserved 
Table 1: Baseline characteristics of the study sample by MSP trajectory

\begin{tabular}{|c|c|c|c|c|c|}
\hline \multirow[t]{3}{*}{ Characteristics $^{\dagger}$} & \multirow{3}{*}{$N=6527$} & \multicolumn{4}{|c|}{ Trajectory group } \\
\hline & & Low & High & Increasing & Decreasing \\
\hline & & $n=2680$ & $n=963$ & $n=1552$ & $n=1332$ \\
\hline Age, (mean $\pm S D)$ & $49.64 \pm 6.53$ & $49.61 \pm 6.74$ & $50.47 \pm 6.15$ & $48.72 \pm 6.28$ & $50.15 \pm 6.52$ \\
\hline \multicolumn{6}{|l|}{ Gender, (n, \%) } \\
\hline Men & 1197 & 609 (22.7) & 110 (11.4) & 232 (15.0) & 246 (18.5) \\
\hline Women & 5330 & 2071 (77.3) & $853(88.6)$ & $1320(85.0)$ & $1086(81.5)$ \\
\hline \multicolumn{6}{|l|}{ Behavioral factors } \\
\hline \multicolumn{6}{|l|}{ Smoking, (n, \%) } \\
\hline Yes & 1549 & 596 (29.5) & 227 (32.5) & 393 (34.1) & 333 (33.1) \\
\hline No & 3329 & $1423(70.5)$ & 472 (67.5) & 760 (65.9) & 674 (66.9) \\
\hline BMI, (mean $\pm S D)$ & $25.42 \pm 4.26$ & $24.78 \pm 3.87$ & $26.51 \pm 4.52$ & $25.91 \pm 4.69$ & $25.36 \pm 4.10$ \\
\hline \multicolumn{6}{|l|}{ LTPA } \\
\hline Low & 1596 & 578 (21.6) & 265 (27.5) & 399 (25.7) & 354 (26.6) \\
\hline Moderate & 2754 & $1054(39.3)$ & 444 (46.1) & $698(45.0)$ & 558 (41.9) \\
\hline
\end{tabular}

This article is protected by copyright. All rights reserved 


\begin{tabular}{llllll}
\hline Vigorous & 2177 & $1048(39.1)$ & $254(26.4)$ & $455(29.3)$ & $420(31.5)$ \\
Musculoskeletal comorbidities & & & & \\
0 & 4779 & $2191(92.5)$ & $539(65.7)$ & $1087(81.6)$ & $962(84.4)$ \\
$1+$ & 883 & $178(7.5)$ & $281(34.3)$ & $246(18.4)$ & $178(15.6)$ \\
Work status & & & & & \\
Full time work & 5902 & $2431(91.9)$ & $839(88.3)$ & $1432(93.2)$ & $1200(91.2)$ \\
Part time work & 257 & $108(4.1)$ & $37(3.9)$ & $56(3.7)$ & $56(4.3)$ \\
$\begin{array}{l}\text { Part-time pension } \\
\text { Other cause for not }\end{array}$ & 181 & $69(2.6)$ & $56(5.9)$ & $25(1.6)$ & $31(2.4)$ \\
being at work & 106 & $36(1.4)$ & $18(1.9)$ & $23(1.5)$ & $29(2.2)$ \\
Socioeconomic & & & & & \\
position & & & & & \\
High & 3347 & $1563(59.4)$ & $361(38.0)$ & $746(49.1)$ & $677(51.8)$ \\
Low & 3059 & $1068(40.6)$ & $588(62.0)$ & $773(50.9)$ & $630(48.2)$ \\
GHQ (common mental & & & & & \\
disorders) & & & & & \\
No & 3429 & $1744(71.5)$ & $319(35.9)$ & $678(48.7)$ & $688(55.5)$ \\
Low & 737 & $234(9.6)$ & $134(15.1)$ & $210(15.1)$ & $159(12.8)$ \\
High & 1793 & $461(18.9)$ & $436(49.0)$ & $504(36.2)$ & $392(31.6)$ \\
\hline
\end{tabular}

${ }^{\dagger}$ Not all variables summed up to $100 \%$ due to missing values. 
Table 2: Associations of the baseline General Health Questionnaire (GHQ12) score, age, gender, socioeconomic position and musculoskeletal comorbidities, with MSP trajectory membership. Odds ratios (OR) and their $95 \%$ confidence intervals (Cls) from multinomial logistic regression models.

\begin{tabular}{|c|c|c|c|c|c|c|}
\hline & \multicolumn{6}{|c|}{ ORs and $95 \%$ Cls for trajectory membership } \\
\hline & \multicolumn{3}{|c|}{ Model I } & \multicolumn{3}{|c|}{ Model II } \\
\hline & High vs. low & Increasing vs. low & Decreasing vs. low & High vs. low & Increasing vs. low & Decreasing vs. low \\
\hline No & 1 & 1 & 1 & 1 & 1 & 1 \\
\hline High & $5.17(4.33-6.17)$ & $2.81(2.41-3.28)$ & $2.15(1.83-2.53)$ & $5.30(4.31-6.53)$ & $2.67(2.25-3.18)$ & $2.18(1.82-2.62)$ \\
\hline \multicolumn{7}{|c|}{ Age (years) } \\
\hline 40 & 1 & 1 & 1 & 1 & 1 & 1 \\
\hline 45 & $1.47(1.14-2.90)$ & $1.32(1.09-1.59)$ & $1.05(0.84-1.30)$ & $1.40(1.03-1.89)$ & $1.43(1.14-1.79)$ & $0.93(0.73-1.19)$ \\
\hline \multicolumn{7}{|l|}{ Gender } \\
\hline Men & 1 & 1 & 1 & 1 & 1 & 1 \\
\hline Women & $2.28(1.83-2.83)$ & $1.67(1.41-1.97)$ & $1.30(1.10-1.53)$ & $2.22(1.68-2.93)$ & $1.46(1.19-1.80)$ & $1.17(0.96-1.43)$ \\
\hline Socioeco & & & & & & \\
\hline
\end{tabular}

This article is protected by copyright. All rights reserved 


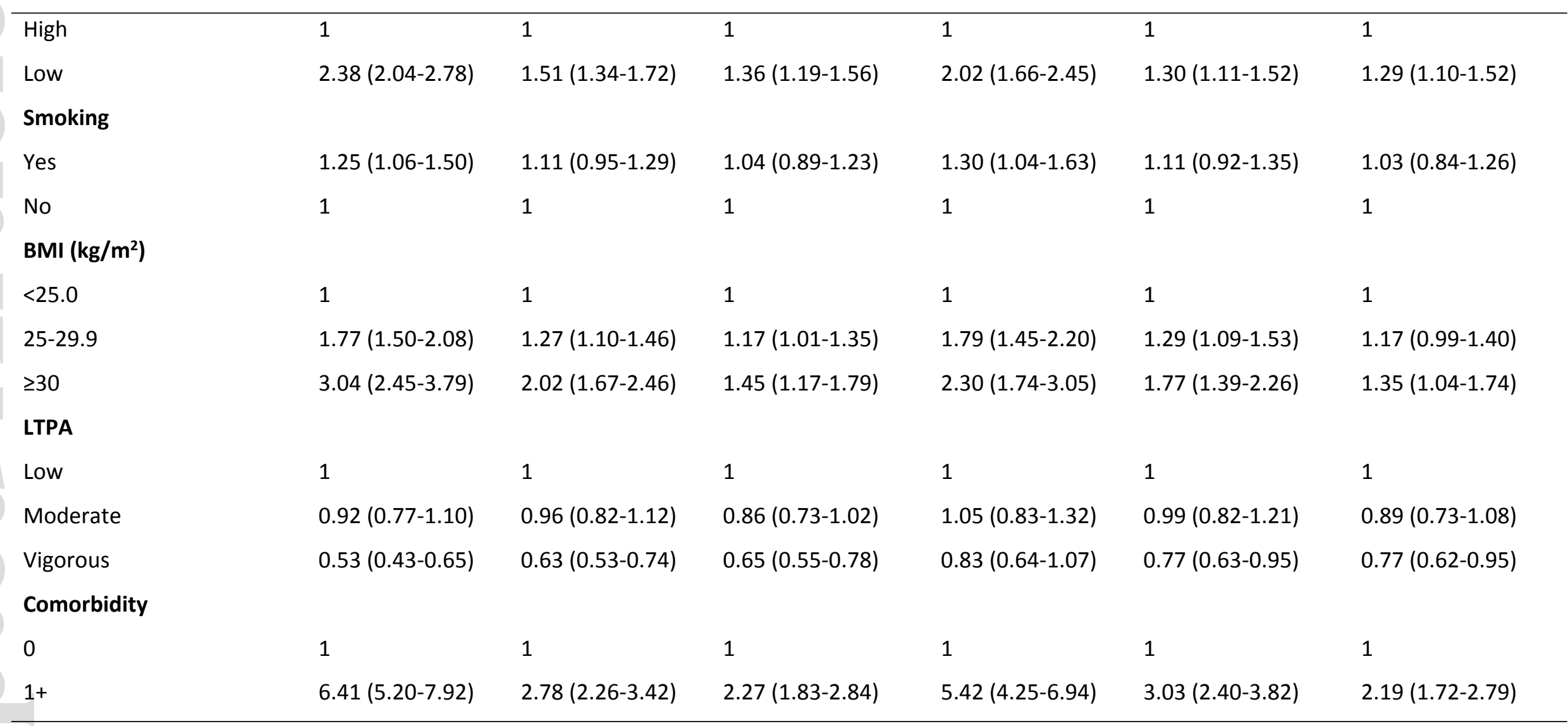

Model I: unadjusted OR and their $95 \% \mathrm{Cl}$

Model II: Simultaneous adjustment of all variables used in the table and work status at baseline.

${ }^{\dagger}$ For $\mathrm{GHQ}$, higher scores indicate the presence of common mental disorders. 
Table 3: Distribution of the mean General Health Questionnaire (GHQ12) score and pain sites at different time points according to trajectory group

\section{Trajectory group}

\begin{tabular}{|c|c|c|c|c|c|c|}
\hline \multirow{2}{*}{\multicolumn{2}{|c|}{$\mathrm{N}=6527$}} & & & & & \multirow[b]{2}{*}{$P$-Value ${ }^{\dagger}$} \\
\hline & & $\begin{array}{c}\text { Low } \\
n=2680\end{array}$ & $\begin{array}{c}\text { High } \\
n=963\end{array}$ & $\begin{array}{c}\text { Increasing } \\
n=1552\end{array}$ & $\begin{array}{c}\text { Decreasing } \\
n=1332\end{array}$ & \\
\hline \multicolumn{7}{|c|}{ GHQ, (mean $\pm S D)$} \\
\hline GHQ 2002 & 6487 & $1.30 \pm 2.61$ & $2.97 \pm 3.51$ & $2.12 \pm 3.25$ & $2.13 \pm 3.17$ & $<0.001$ \\
\hline GHQ 2007 & 5959 & $1.10 \pm 3.65$ & $3.06 \pm 3.65$ & $2.18 \pm 3.24$ & $1.78 \pm 2.96$ & $<0.001$ \\
\hline GHQ 2012 & 6762 & $1.04 \pm 2.33$ & $2.93 \pm 3.64$ & $2.16 \pm 3.26$ & $1.26 \pm 2.46$ & $<0.001$ \\
\hline \multicolumn{7}{|c|}{ MSP, (mean $\pm S D)$} \\
\hline 2002 & 6527 & 0 & $1.92 \pm 1.20$ & $0.42 \pm 0.59$ & $1.01 \pm 0.82$ & $<0.001$ \\
\hline 2007 & 5847 & 0 & $2.62 \pm 1.12$ & $1.19 \pm 1.01$ & $0.64 \pm 0.65$ & $<0.001$ \\
\hline 2012 & 6527 & $0.12 \pm 0.32$ & $2.40 \pm 1.18$ & $1.43 \pm 0.93$ & 0 & $<0.001$ \\
\hline
\end{tabular}

${ }^{+} P$-value for the difference within the trajectory group.

\section{Figure Legend}

Figure 1: Developmental trajectories of the number of musculoskeletal pain sites (0-4) in a 10 year followup ( $n=6527)$. 


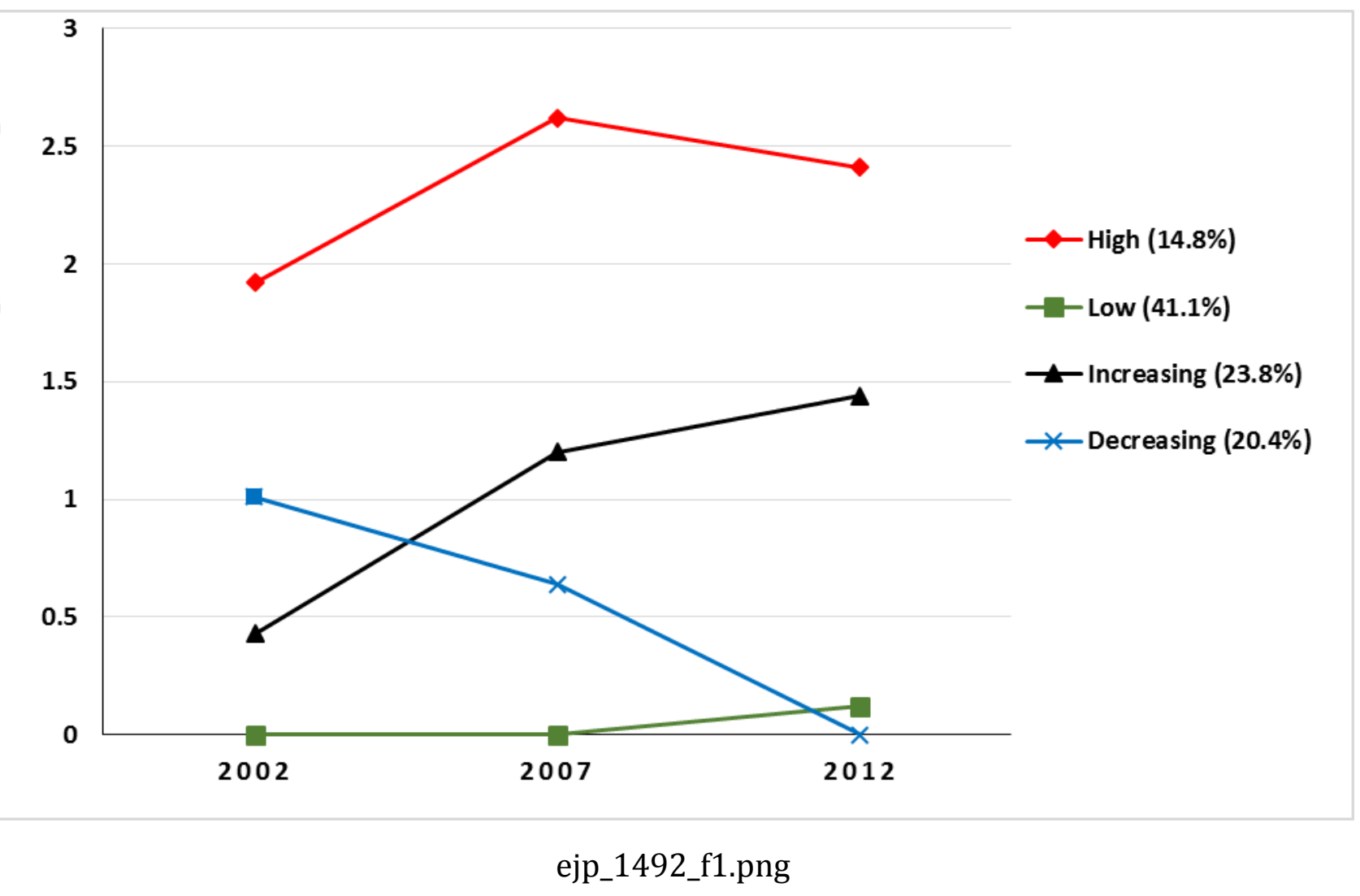

This article is protected by copyright. All rights reserved 